Indian J. Anim. HIth. (2019), 58(2) : 239-242

DOI: https://doi.org/10.36062/ijah.58.2.2019.239-242

Short Communication

\title{
RENAL FAILURE IN A LABRADOR RETRIEVER DOG - A CASE STUDY
}

\author{
J. MUKHERJEE*, P. MUKHERJEE ${ }^{1}$, D. GHOSH ${ }^{2}$ \\ A. K. MAJI ${ }^{2}$ AND P. K. DAS \\ Department of Veterinary Physiology \\ Faculty of Veterinary and Animal Sciences \\ West Bengal University of Animal and Fishery Sciences \\ 37, K. B. Sarani, Kolkata-700 037, West Bengal, India
}

\begin{abstract}
The present study describes different diagnostic modalities along with treatment options for renal failure in a dog. A 7 year old male Labrador Retriever dog was presented with the complaints of anorexia since last one month with debility, progressive weight loss and occasional haematuria. Ultrasonographic scan revealed cystitis, shrunken left kidney with prostate enlargement. Haemato-biochemical reports revealed high BUN and creatinine along with decreased haemoglobin and lymphocytopenia. Urine analysis revealed proteinuria. Based on the clinical findings, the patient was diagnosed with chronic renal failure and therapeutic interventions started accordingly. But, in spite of commencement of treatment patient died within 2 days.
\end{abstract}

Key word: Haematology; Renal failure; Ultrasonography

A male Labrador retriever dog aged 7 years was referred to the University Clinics, Belgachia, Kolkata with the history of anorexia since last one month, debility, progressive weight loss and occasional haematuria. The dog also exhibited ulceration and uremic odour in mouth.

The physical examination revealed normal heart rate $(132 \mathrm{bpm})$, respiration rate $(31 / \mathrm{min})$ and rectal temperature $\left(101.3^{\circ} \mathrm{F}\right)$.

The complete blood count reports revealed haemoglobin $7.5 \mathrm{gm} \%$, total leukocyte count (TLC) 10,600 /cumm and platelet count $260 \mathrm{X}$
$10^{3} /$ cumm. The differential leukocyte count (DLC) exhibited neutrophil 89\%, eosinophil $01 \%$, monocyte $01 \%$ and lymphocyte $9 \%$.

The liver function tests appeared normal. However, kidney function tests showed increased BUN (202 mg/dL) and creatinine $(35 \mathrm{mg} / \mathrm{dL})$.

The urine was collected through catheterization and proteinuria along with isosthenuria (specific gravity of urine: 1.013) appeared in urine analysis report along with unorganised granular casts in urine sediments.

*Corresponding Author

${ }^{1}$ Department of Veterinary Clinical Complex, WBUAFS, Mohanpur, Nadia

${ }^{2}$ Department of Veterinary Surgery and Radiology, WBUAFS, Kolkata-700 037 
Abdominal radiograph appeared with distended urinary bladder and highly enlarged prostate gland (Fig. 1).

Cystitis (urinary bladder wall thickness 0.83 $\mathrm{cm}$ ) along with the presence of sludge (Fig. 2) was appreciated upon ultrasonography. Enlarged prostate $(4.5 \times 5.1 \mathrm{~cm})$ was also noticed (Fig. 3) which supported radiographic findings. The right kidney was shrunken (3.1
$X 3.7 \mathrm{~cm}$ ) with irregular boundary (Fig.4). The cortico-medullary demarcation in this kidney was also lost. The left kidney showed normal size $(4.03 \times 7.08 \mathrm{~cm})$ without clear corticomedullary demarcations (Fig. 5).

In this case the patient was treated with lactated Ringer's solution and ACE inhibitors enalapril (a) $0.5 \mathrm{mg} / \mathrm{kg}$ BID PO. Epakitin ${ }^{\circledR}$ powder (®Vetoquinol)@1 scoop/5kg/body weight/ day

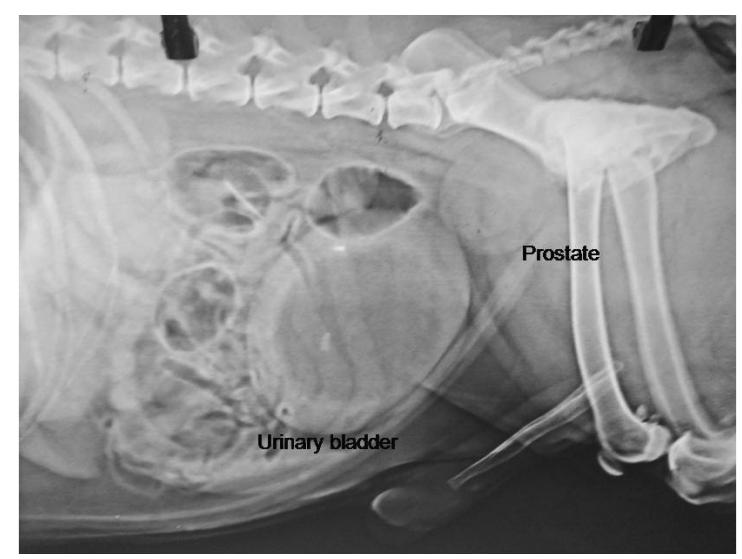

Fig. 1. Abdominal radiograph showing enlarged prostate and urinary bladder

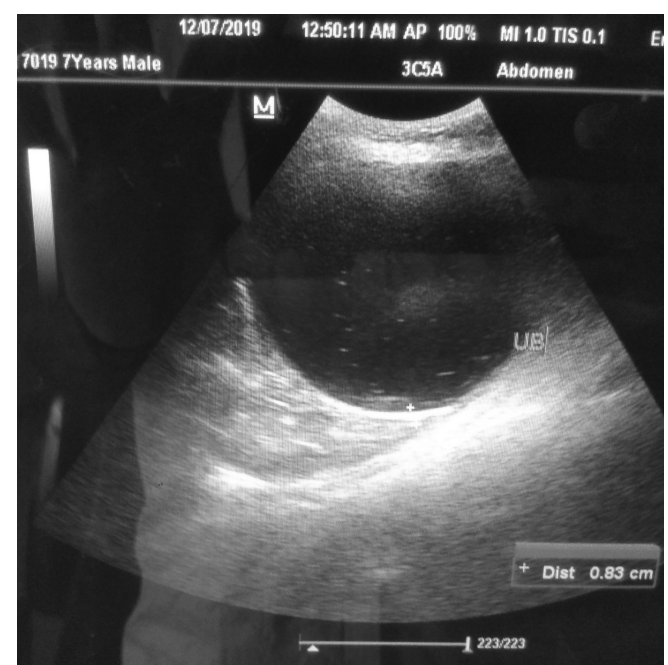

Fig. 2. Sonograph of urinary bladder showing cystitis

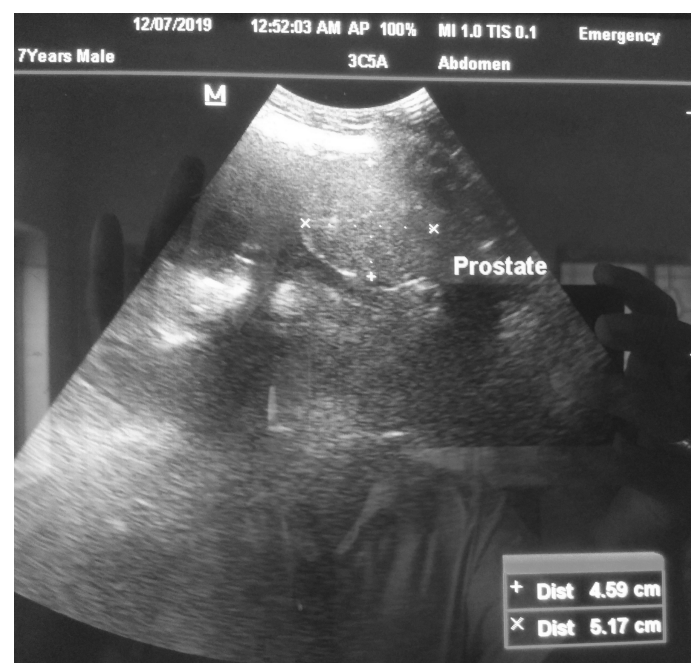

Fig. 3. Sonograph showing prostate 


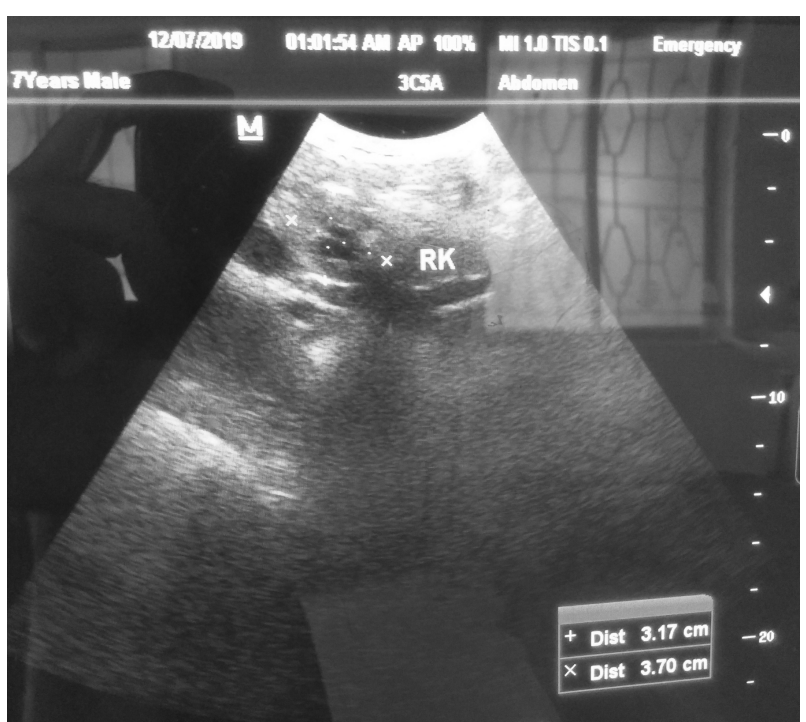

Fig. 4. Sonograph showing right kidney

was advised as it reduces serum phosphate levels and improves kidney health. Injection darbepoetin@0.5 $\mu \mathrm{g} / \mathrm{kg} \mathrm{SC}$ once weekly was also advised as it stimulates erythropoiesis (Fiocchi et al., 2017).

But, in spite of commencement of treatment patient died within 2 days as prognosis of the patient depends upon severity of the disease, response of the patient to the treatment as well as proper staging of CKD as per International Renal Interest Society (IRIS) guidelines.

Chronic kidney disease (CKD) is common in dogs and cats occurring due to permanent damage to the functional nephrons (Chan et al., 2013). Ultrasonographic appearances of kidneys in chronic kidney diseases are decreased size, thinning of parenchyma and loss of corticomedullary demarcation (O'Neill, 2000). Here in this case, the right kidney seemed shrunken, together with the loss of cortico-medullary demarcation and irregular boundaries which are considered to be the cardinal signs of kidney

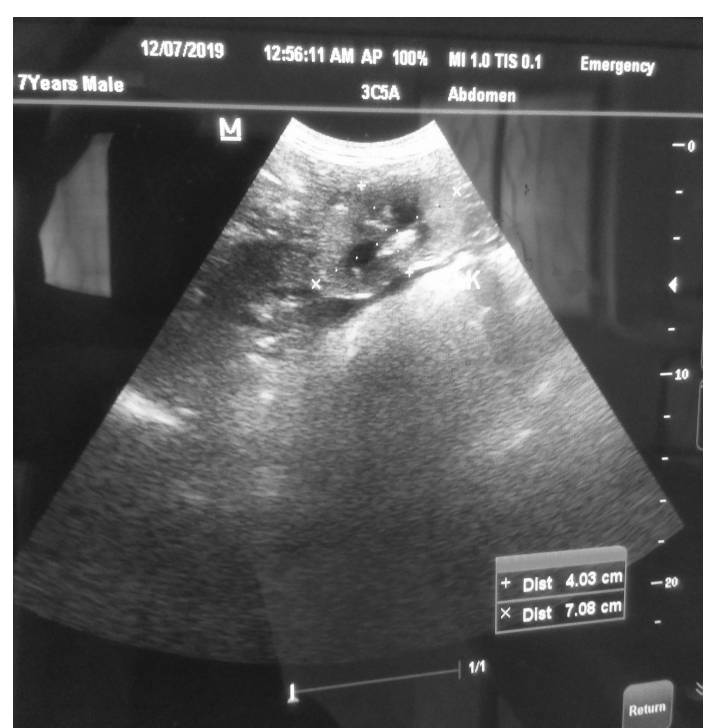

Fig. 5. Sonograph showing left kidney

damage. However, the left kidney showed normal size and shape without corticomedullary demarcations. In CKD, patients can maintain the renal functions with one functional kidney over a period due to compensatory mechanisms (Grauer, 2009). The complete blood count in this investigation showed lymphocytopenia which was in accordance with the earlier reports of Kralova et al. (2010). The prostate enlargement might have aggravated the situation as benign prostatic hyperplasia was correlated with chronic renal failure in human (Rule et al., 2005).

The kidney has important role in maintaining phosphorus homeostasis by controlling the excretion through urine. In chronic kidney disease there is impairment of renal excretion of phosphorus, as a consequence phosphate retention occurs in body that in turn causes further hyperphosphatemia. Hence, controlling of phosphorus in CKD is very much important to prevent further deterioration of the condition of 
the patient (Geddes et al., 2013; Polzin, 2013). Proteinuria is considered as main reason that provokes the patient towards renal failure now days (Burton and Harris, 1996; Remuzzi, 1999; Walls, 2001). In this case ACE inhibitor was used, as previous study by several authors showed that enalapril decreases the level of proteinuria and slows down the kidney damage as a result increase the lifespan of the patient (Jacob et al., 2005).

The treatment modalities of CKD are aimed

\section{REFERENCES}

Chan KW, Ping TY, Chou SJ, Zheng ZJ, Yang WC et al., 2013. Treatment of an elderly dog with concurrent heart disease and acute uremia by hemodialysis. Taiwan Vet J, 39 (3): 150-157

Grauer GF, 2009. Acute renal failure and chronic kidney disease. In: Nelson RW, Couto CG. Small Animal Internal Medicine, $4^{\text {th }}$ edn., Mosby, Columbus, pp645-655

O'Neill WC, 2000. Sonographic evaluation of renal failure. Am J Kidney Dis, 35(6): 1021-1038

Rule AD, Lieber MM and Jacobsen SJ, 2005. Is benign prostatic hyperplasia a risk factor for chronic renal failure? J Urol, 173(3): 691-696

Ross SJ, Osborne CA and Kirk CA, 2006. Clinical evaluation of dietary modification for treatment of spontaneous chronic kidney disease in cats. J Am Vet Med Assoc, 229: 949957

Jacob F, Polzin DJ, Osborne CA, Neaton JD, Kirk CA et al., 2005. Evaluation of the association between initial proteinuria and morbidity rate or death in dogs with naturally occurring chronic renal failure. J Am Vet Med Assoc, 226(3): 393-400

Fiocchi EH, Cowgill LD, Brown DC, Markovich JE, Tucker S et al., 2017. The use of mainly to slower down the progressive kidney damage by supportive therapy, as it is very difficult to restore irreversible kidney damage by therapeutic interventions (Ross et al., 2006).

Conflict of interests: The authors declare there is no conflict of interests amongst them.

\section{ACKNOWLEDGEMENT}

Authors are extremely grateful to the ViceChancellor, WBUAFS for providing financial support to complete the study.

darbepoetin to stimulate erythropoiesis in the treatment of anemia of chronic kidney disease in dogs. J Vet Intern Med, 31(2): 476-485

Burton C and Harris KPG, 1996. The role of proteinuria in the progression of chronic renal failure. Am J Kidney Dis, 27: 765-775

Remuzzi G, 1999. Nephropathic nature of proteinuria. Curr Opin Nephrol Hypertens, 8: 655-663

Walls J, 2001. Relationship between proteinuria and progressive renal disease. Am J Kidney Dis, 37(suppl 2): S13-S16

Polzin DJ, 2013. Evidence-based step-wise approach to managing chronic kidney disease in dogs and cat. J Vet Emerg Crit Care, 23: 205-215

Geddes RF, Finch NC, Syme HM and Elliot J, 2013. The role of phosphorus in the pathophysiology of chronic kidney disease. J Vet Emerg Crit Care, 23: 122-133

Kralova S, Leva L and Toman M, 2010. Changes in lymphocyte function and subsets in dogs with naturally occurring chronic renal failure. Can J Vet Res, 74(2): 124-129 